\title{
Violência de gênero: uma questão cultural? ${ }^{1}$
}

\author{
¿Violencia de género: una cuestión cultural? \\ Gender violence: a cultural issue?
}

Lais Olimpio da Silva ${ }^{2}$

\begin{abstract}
Resumo
O presente trabalho tem como objetivo elucidar a relação entre cultura e violência de gênero, abordando as dimensões históricas, econômicas e sociais da constituição desta forma específica de violência na contemporaneidade. A violência de gênero, enquanto fenômeno socialmente construído, se expressa para além de manifestações visíveis - denominada como violência aberta - atingindo de forma específica mulheres e homens, desde a mais tenra idade até a velhice. Compreendendo gênero enquanto padrão de organização social, que estabelece relações de poder diferenciadas entre mulheres e homens, podemos identificar uma forma sutil de reprodução da violência, uma violência estrutural e ressignificada de acordo com os movimentos dialéticos existentes na sociedade. É possível enxergar a dimensão cultural quando analisamos a reprodução acrítica de ações que reiteram esta forma de violência pela observação das inúmeras propagandas televisivas que objetificam corpos femininos; quando temos atrizes e atores com as mesmas características físicas interpretando reiteradamente os mesmos personagens nas telenovelas e quando ouvimos a idealização de "casal perfeito" nas músicas, por exemplo. Encontramos uma construção de padrão ideal balizado pelo viés branco, heterossexual e com boas condições financeiras, que afetam diretamente o modo de ser de toda a sociedade, com uma reprodução mandatória que não corresponde à realidade social da maior parte da população brasileira. Utilizando o método materialista histórico dialético, buscaremos compreender a relação que a idealização de papéis sociais atribuídos aos sexos feminino e masculino têm com a reprodução cultural da violência de gênero e refletir suas implicações nas relações sociais.
\end{abstract}

Palavras-Chave: Relações de Gênero; Violência de gênero; Cultura.

\section{Resumen}

El presente trabajo tiene como objetivo elucidar la relación entre cultura y violencia de género, abordando las dimensiones históricas, económicas y sociales de la constitución de esta forma específica de violencia en la contemporaneidad. La violencia de género, como fenómeno socialmente construido, se expresa más allá de manifestaciones visibles - denominada como violencia abierta - alcanzando de forma específica a mujeres y hombres, desde la infancia hasta la vejez. En cuanto a género como patrón de organización social, que establece relaciones de poder diferenciadas entre mujeres y hombres, podemos identificar una forma sutil de reproducción de la violencia, una violencia estructural y resignificada de acuerdo con los movimientos dialécticos existentes en la sociedad. Es posible ver la dimensión cultural cuando analizamos la reproducción acrítica de acciones que reiteran esta forma de violencia por la observación de los innumerables propagandas televisivas que objetivan cuerpos femeninos; cuando tenemos actrices y actores con las mismas características físicas interpretando reiteradamente los mismos personajes en las telenovelas y cuando oímos la idealización de "pareja perfecta" en las canciones, por ejemplo. Se encuentra una construcción de patrón ideal balizado por el sesgo blanco, heterosexual y con buenas condiciones financeiras. Utilizando el método materialista histórico dialéctico, buscaremos comprender la relación que la idealización de papeles sociales atribuidos a los sexos femenino y masculino tienen con la reproducción cultural de la violencia de género y reflejar sus implicaciones en las relaciones sociales.

\footnotetext{
${ }^{1}$ Artigo apresentado no Simpósio Temático Jovens Pesquisadores Latino-americanos (Graduandos) - Temática Livre durante o II Seminário Latino-Americano de Estudos em Cultura - SEMLACult em Foz do Iguaçu/PR, Brasil, 2018.

${ }^{2}$ Bacharel em Serviço Social; Universidade Federal do Estado do Rio de Janeiro - UNIRIO; Rio de Janeiro, Rio de Janeiro, Brasil; lais.102@hotmail.com.
} 
Palabras clave: Relaciones de género; Violencia de género; Cultura.

\begin{abstract}
The present paper aims to elucidate the relation existent between Culture and Gender Violence, addressing the historical, economic and social dimensions of the constitution of this specific form of violence in contemporary times. Gender violence, as a socially builded phenomenon, is expressed in addition to visible manifestations termed as "open violence" - specifically targeting women and men, from the earliest age to old age. Understanding gender as a pattern of social organization, which establishes differentiated power relations between women and men, we can identify a subtle form of violence reproduction, a structural violence and resignified according to the existing dialectical movements in society. It is possible to see the cultural dimension when we analyze the uncritical reproduction of actions that reiterate this form of violence by the observation of the numerous television advertisements that objectify women's bodies; when we have actresses and actors with the same physical characteristics repeatedly interpreting the same characters in soap operas and when we hear the idealization of "perfect couple" in the songs, for example. We find an ideal standard construction marked by the white, heterosexual bias and with good financial conditions that directly affect the way of being of the whole society, with a mandatory reproduction that does not correspond to the social reality of the majority of the Brazilian population. Using the dialectical historical materialist method, we will try to understand the relation that the idealization of social roles attributed to the female and male sexes has with the cultural reproduction of gender violence and to reflect its implications in social relations.
\end{abstract}

Keywords: Gender relationships; Gender violence; Culture.

\title{
1. Introdução
}

Analisar a relação existente entre Gênero, Violência e Cultura exige mais do que uma explicação simplista, baseada na aparência dos fatos. É necessário enxergar suas implicações nas variadas dimensões da vida em sociedade, buscando uma leitura da totalidade na qual a mesma se realiza. Com fito de contextualizar e elucidar o ponto de partida adotado na confecção do presente trabalho, trataremos a categoria Gênero como forma padrão de organização da sociedade, diferenciando-a assim da corriqueira utilização biologicista que se tem na definição de macho e fêmea; Violência como fenômeno histórico estrutural que compõe diversas sociedades ao longo da história e Cultura como meio utilizado para legitimar hegemonicamente os interesses de uma classe em detrimento de outra, baseado num aporte historicamente determinado e, portanto, passível de mudanças.

Deste modo, analisaremos as imbricações existentes entre as três categorias mencionadas anteriormente, focando na reprodução cultural da Violência de Gênero em seus mais diversos aspectos, buscando compreender como as relações socias de hierarquização e poder existente entre as mesmas são criadas e reproduzidas de acordo com uma intencionalidade, nem sempre anunciada, presente na dimensão de uma violência estrutural inerente ao modo de produção capitalista. Objetivamos estudar a forma como essas relações desiguais de poder se reproduzem e garantem legitimidade social, histórica e cultural a este fenômeno, apontando reflexões para uma compreensão mais aprofundada desta relação. 


\section{Gênero enquanto categoria analítica da sociedade:}

Saffioti (1997) chama atenção para a constituição da sociedade brasileira, marcada pela divisão em classes sociais e atravessada pelas contradições de gênero e de raça/etnia, tendo o cuidado teórico de não dividir a mesma em três linhas de pensamentos paralelos, mas sim integrando-os e analisando os resultados decorrentes destas imbricações. Pretendemos aqui compreender a relevância das distinções de gênero na análise da sociedade sem dissociar os três determinantes sociais apontados acima pela autora.

A sustentação de gênero como categoria ontológico-social significa sua compreensão enquanto fenômeno fundante do Ser Social, pois se expressa como um padrão de organização social, conforme apontam Veloso e Bezerra (2004). Os autores implicam sua abrangência para além de questões biologicistas, que fazem referência ao sexo biológico dos indivíduos, apresentando a categoria de forma contrária à explicação dada pelo senso comum à existência das desigualdades sociais entre mulheres e homens. Ou seja, explicam que não se trata apenas de apontar e definir "papéis sociais" atribuídos ao sexo feminino ou ao sexo masculino, mas sim entender como essa lógica se reproduz e a quais interesses ela atende.

A negação da existência de uma essência natural, feminina ou masculina, imutável e universal é um ponto de partida importante para compreendermos a forma como as relações de gênero foram criadas e permanecem mutáveis na sociedade, adaptando-se de acordo com o modo de produção vigente. Essa característica histórica e social desta categoria explica a forma como "a divisão do poder realizada entre homens e mulheres, mediada pelo gênero, ocorre de maneira desigual, tendendo a favorecer os primeiros." (VELOSO e BEZERRA, 2004, p. 108).

Ou seja, a concepção das relações de gênero enquanto fenômeno social e histórico, portanto passível de transformação, representa um avanço científico no que tange à forma como as mulheres são tratadas e idealizadas hegemonicamente nesta sociedade pautada pela cultura patriarcal, intensificada pelo modo de produção capitalista. Rezende (2015) explica que esta cultura patriarcal precede o modo capitalista de produção e organização da sociedade, referindo-se ao patriarcado não apenas como uma forma tradicional de dominação e exploração ultrapassada pelo avançar da história, mas como "um sistema de opressão que permanece e se atualiza mesmo com o avanço do capitalismo e da democracia liberal, constituindo-se como característica das sociedades modernas.” (REZENDE, 2015, p.14) 
Enxergar a categoria gênero como determinante social não significa engessar a sociedade tal como ela se apresenta, nem mesmo negar o espaço da subjetividade inerente a cada sujeito social. Não se trata de culpabilizar as mulheres pelo atual lugar que ocupam no atual modo de produção e reprodução das relações sociais, mas sim apontar a relevância desta categoria na constituição diferenciada das relações de poderes entre mulheres e homens.

A hierarquização das atividades de produção e reprodução social, e, portanto, a hierarquização de sexo, impõe a criação de um sistema de um sistema de divisão social do trabalho, conforme apontam Hirata e Kergoat (2007, p. 599). Este sistema apontado pelas autoras "tem como característica a designação prioritária dos homens à esfera produtiva e das mulheres à esfera reprodutiva e, simultaneamente, a apropriação pelos homens das funções com maior valor social adicionado". Com base nessa contradição fundamental do modo de produção capitalista é que situamos a categoria de gênero e assim também o surgimento do fenômeno da violência de gênero e a sua manutenção por meio do âmbito cultural.

Sendo assim, temos que gênero perpassa as relações entre as mulheres, entre mulheres e homens e entre os próprios homens; delimitando, impondo e exigindo certas características de cada um desses grupos específicos, não de acordo com a "natureza" de cada um, mas sim de acordo com o que é social e culturalmente esperado de cada um desses grupos, caracterizando então uma forma de violência psicológica contra os que não se "encaixam" no padrão que lhes foi imposto.

\section{1 - Violência de Gênero}

Para compreender melhor o que chamamos violência de gênero é necessário entender primeiramente o que é Violência. Enquanto categoria analítica, trata-se de um fenômeno complexo e que assume características específicas no capitalismo, entretanto, é importante ressaltar que esteve presente em todos os estágios de desenvolvimento da sociabilidade humana, aparecendo de formas diferenciadas a depender do contexto histórico analisado.

(...) a violência aparece nas relações sociais tanto como forma de transformação dessas relações, quanto como modo de dominação, coerção e manutenção de uma determinada ordem. Vincula-se, na história humana, à criação e à transformação da própria sociedade, possuindo um papel importante, seja no sentido revolucionário, contribuindo para subverter a ordem estabelecida, seja para conservá-la. (ROS, 2011, p. 3)

Os diferentes empregos da categoria Violência, conforme descritos acima, podem ser funcionais ou não à manutenção do Status Quo, a depender da forma como a mesma é 
utilizada. A autora aponta que o aparecimento da violência nas relações sociais está ligado a elementos fundantes desta ordem social, tais como a propriedade privada e a divisão da sociedade em classes sociais, o que caracteriza uma violência estrutural que não é levada em conta na elaboração de políticas públicas de combate à violência, estas últimas destinadas exclusivamente ao enfrentamento de questões mais aparentes, como a denominada violência urbana, violência doméstica e etc., não possuindo assim um viés revolucionário que a violência enquanto práxis propiciaria.

Adicionamos a isso a divisão sexual e racial do trabalho, marcada também pelas contradições de raça/etnia como elementos fundantes que determinam a reprodução da violência estrutural inerente ao capitalismo. Assim, a violência de gênero, e todas as suas dimensões e refrações na dinâmica social, podem ser consideradas como uma forma de reproduzir a violência estrutural do modo de produção capitalista, pois representa uma forma de manter e reproduzir a desigualdade social entre mulheres e homens, sendo agravadas quando pensamos a situação das mulheres negras.

Percebe-se que a violência que assola este processo é de nível estrutural, pois é no âmbito da construção social e cultural imposta pelo modo de produção capitalista que o patriarcado é aprofundado, ganhando cada vez mais legitimidade para justificar ideologicamente os abusos cometidos, não importando em que ordem a mesma se realize, abrangendo a violência física, sexual, psicológica, patrimonial, moral, simbólica e etc.

A centralidade das ações violentas incide sobre a mulher, quer sejam estas
violências físicas, sexuais, psicológicas, patrimoniais ou morais, tanto no âmbito
privado-familiar como nos espaços de trabalho e públicos. Não se trata de adotar
uma perspectiva ou um olhar vitimizador em relação à mulher (...), mas destacar que
a expressiva concentração deste tipo de violência ocorre historicamente sobre os
corpos femininos e que as relações violentas existem porque as relações assimétricas
de poder permeiam a vida rotineira das pessoas. (BANDEIRA, 2014, p. 451)

O avanço presente na promulgação da lei 11.340/2006, conhecida como lei Maria da Penha, que cria mecanismos para coibir a violência doméstica e familiar ao definir as bases materiais da violência física, sexual, patrimonial e moral não é suficiente para questionar a reprodução social da violência em seu âmbito estrutural, pois categoriza as formas de violência de maneira estanque, deixando de lado os demais aspectos fundantes deste tipo de violência; vinculados à dimensão de gênero presente na formação do ser social, que atribui relações de poder diferenciados nesta sociedade, legitimando culturalmente a submissão das mulheres aos homens. 
A inclusão da mulher nesta sociedade se dá de forma subalternizada e dependente, pautada pela imposição da definição familiar heteronormativa e nuclear burguesa. É determinada a sua função social, onde a mesma estará, responsável pela criação e educação dos filhos, dos afazeres domésticos e os demais que visem a manutenção desta ordem, no que tange a reprodução social das relações sociais capitalistas, pautada pela divisão sexual do trabalho ${ }^{3}$. Esta visão é problematizada por Saffioti (1997) quando a mesma sinaliza que não podemos associar o fato d'as mulheres serem vítimas da violência de gênero com uma pseudo passividade por parte das mesmas, pois "para poder ser cúmplice do homem, a mulher teria de se situar no mesmo patamar que seu parceiro na estrutura de poder. Só este fato a colocaria em condições de consentir na violência masculina.” (SAFFIOTI, 1997, p.71)

Ainda sobre a presença da organização patriarcal na sociedade atual, a autora reforça:

Como os demais fenômenos sociais, também o patriarcado está em permanente transformação. Se, na Roma antiga, o patriarca detinha poder de vida e morte sobre sua esposa e seus filhos, hoje tal poder não mais existe, no plano de jure. Entretanto, homens continuam matando suas parceiras, às vezes com requintes de crueldade, esquartejando-as, ateando-lhes fogo, nelas atirando e as deixando tetraplégicas etc. O julgamento destes criminosos sofre, é óbvio, a influência do sexismo reinante na sociedade, que determina o levantamento de falsas acusações devassa é a mais comum - contra a assassinada. A vítima é transformada rapidamente em ré, procedimento este que consegue, muitas vezes, absolver o verdadeiro réu. (SAFFIOTI, 2004, p.45-6) Grifos originais.

Contudo, afirmamos que para além da violência aberta, onde existe agressão física, também é necessário analisar os demais aspectos que permeiam a violência de gênero, incluindo seus matizes psicológicos, morais, simbólicos. Portanto, deve-se buscar combater estruturalmente a forma como tais violências se reproduzem e ditam a forma de sociabilidade atual, mostrando-se presente em todos os âmbitos da vida social, por meio de diferentes relações, mas sempre atendendo ao objetivo maior de perpetuar este sistema patriarcal dentro do capitalismo, aprofundando e enraizando a divisão sexual das relações de poder.

A utilização indiscriminada de propagandas televisivas onde o corpo feminino é uma estratégia de chamar atenção para o produto ou a reiterada veiculação de pares românticos em filmes, novelas e letras de música também podem ser interpretadas como um meio de manter o molde patriarcal apropriado pela organização capitalista dessa sociedade. Trata-se de uma violência simbólica que não é enxergada, nem mesmo com o avanço conquistado pela lei

\footnotetext{
3 "Essa forma particular da divisão social do trabalho tem dois princípios organizadores: o princípio de separação (existem trabalhos de homens e trabalhos de mulheres) e o princípio hierárquico (um trabalho de homem "vale" mais que um trabalho de mulher)" (HIRATA e KERGOAT, 2007, p. 599)
} 
Maria da Penha, que ainda não elenca a violência simbólica como meio de subjugação feminina.

Exemplo disso é a forma como o Estado e a sociedade legitimam a reprodução desta forma de violência ao enxergar separadamente o que corresponde ao âmbito público e ao privado, reforçado pela máxima do dito popular "em briga de marido e mulher, não se mete a colher". Saffioti (2001, p.136) explicita que se constitui um grande equivoco a separação entre estrutura de classes e relações interpessoais pois "nenhuma relação social se passa fora da estrutura. Todas elas obedecem às normas que estruturam a sociedade por inteiro". Ratificando o slogan feminista que diz "O pessoal é político", em contraponto ao ditado mencionado anteriormente.

\section{2 - O papel da cultura na perpetuação da violência de gênero}

Conforme José Luiz dos Santos, a cultura refere-se a todos os aspectos de uma realidade social, representa o conhecimento, as ideias e crenças da população. $\mathrm{O}$ autor aponta que Ideologia não o mesmo que cultura, porém, defende que é por meio dessa que podemos perceber a forma como se dá a manutenção de determinado modo de vida, historicamente datado.

As relações sociais de poder são estabelecidas nesta sociedade de acordo com os interesses da classe hegemonicamente dominante, que as mantém e as reproduzem por meio da cultura criada e legitimada em torno deste processo de socialização. Conforme vimos, as relações de gênero são componentes essências para a compreensão e estudo da sociedade como um todo e assim como a mesma, a cultura também se constitui enquanto importante fator de análise, pois expressa o modo de ser das sociedades organizadas ao longo do decurso histórico.

Saffioti (2001) defende que Violência de Gênero é um conceito amplo que abrange mulheres, crianças e adolescentes de ambos os sexos pois está vinculada a forma como homens estão autorizados culturalmente, ou ao menos recebem essa tolerância da sociedade, para punir o que lhes parece como desvio. Para elucidar este processo, a autora trás a combinação da categoria exploração-dominação de gênero, onde estão sintetizadas as formas como a violência se dá, pois não se trata apenas de uma questão subjetiva de um homem "agressivo", mas sim toda uma construção social em torno do que se impõe sobre as pessoas, pautada pela divisão sexual das relações de poder. 
O papel da cultura é de suma importância para destacarmos e exemplificarmos como a divisão social das relações de poder é realizada de forma díspare entre mulheres e homens, favorecendo estes últimos em detrimento das primeiras, enaltecendo a forma como os mesmos são enxergados e idealizados nesta sociedade e depreciando a forma como as mulheres são vistas socialmente, naturalizando as expressões da violência de gênero cometidas contra as mulheres, crianças, adolescentes e até mesmo contra os homens.

Esse padrão é reforçado por meio das manifestações culturais que, apesar da aparente diversidade de opções - entre músicas, novelas, filmes, peças teatrais, comerciais de TV e etc. - de entretenimento antigas e atuais, ainda é predominante a representação de um "tipo ideal" do feminino, onde encontramos mulheres dentro do padrão de beleza socialmente difundido como correto: mulheres/mães zelosas, carinhosas, recatadas, frágeis e submissas, que tem como finalidade servir de modelo e inspiração às demais mulheres que ouvem/assistem tais mídias, assim como temos um "tipo ideal" do masculino: homens "malandros", mulherengos, viris, responsáveis pelo sustento da casa e etc. Além, é claro, da representação étnico-racial desses personagens, onde as mulheres negras aparecem em posições de subserviência tanto para os homens quanto para as mulheres brancas e os homens negros são retratados em sua maioria como preguiçosos, desleixados e imorais.

Essa caracterização da violência simbólica de gênero reproduz estruturalmente a violência de gênero. A exemplificação acima demonstra como a cultura e suas expressões culturais são utilizadas para atender aos interesses de reprodução e manutenção da ordem social e do Status Quo patriarcal e racista, apropriado e aprofundado pelo modo de produção capitalista.

Não é a violência que cria a cultura, mas é a cultura que define o que é violência. Ela é que vai aceitar violências em maior ou menor grau a depender do ponto em que nós estejamos enquanto sociedade humana, do ponto de compreensão do que seja a prática violenta ou não. (BAIRROS, 2018)

Essas manifestações culturais afetam a forma das pessoas se relacionarem entre si, e também são reflexos da formação social, histórica e cultural de certas regiões, reproduzindo entre si mesmos formas violentas e tóxicas de conviver em sociedade. $\mathrm{O}$ atual modo de produção e reprodução das relações sociais não permite a ruptura com este sistema de dominação/exploração, pois é fundado a partir desta contradição. Entretanto não é este o motivo para deixarmos de acreditar na possibilidade da emancipação humana, pois a história se faz dialeticamente por meio de movimentos de transformação, cabendo a nós alterarmos a direção do desenvolvimento humano. 


\section{Conclusões}

Suscitamos aqui o debate da Violência de Gênero enquanto parte constituinte da violência estrutural inerente ao modo de produção capitalista, produzindo e reproduzindo as relações de gênero determinadas pelas categorias de classe, gênero e raça/etnia para demonstrar a forma como o capitalismo se utiliza desses fatores para aprofundar a dominaçãoexploração patriarcal por meio de expressões culturais, naturalizando estes fenômenos como se os mesmos fizessem parte de uma natureza inerentemente humana.

Buscamos identificar neste processo os fatores socioculturais que possibilitam o entrelace entre as relações sociais de gênero, a cultura e a reprodução da violência de gênero, ressaltando que a mesma não ocorre apenas de maneira explicita, mas também por meio de mecanismos "sutis" adotados com objetivo de manter a sociedade como está.

Portanto, temos a resposta para a pergunta levantada no título deste artigo. Violência de Gênero não se resume a esfera da cultura, pois requer uma estruturação mais ampla, calcada no âmbito econômico, político e ideo-cultural para ser fundada e reproduzida, não devendo, portanto, ser tratada apenas enquanto uma questão cultural. A busca pela não compartimentalização entre as esferas do econômico, do político e da cultura se dá em acordo com o referencial teórico adotado, onde

$\mathrm{O}$ tripé gênero-raça/etnia-classe exerce pressões numa determinada direção. $\mathrm{O}$ uso de conceito(s) inscrito(s) neste nível assegura o afastamento do relativismo absoluto, tão a gosto de pós-estruturalistas. Com efeito, esta instância do particular (sentido usado por Marx), na qual se faz história, é imprescindível para se evitarem, simultaneamente, o relativismo irrestrito e a fragmentação como traços do conhecimento. (SAFFIOTI, 1997, p.76)

Buscamos observar a totalidade deste fenômeno na sociedade atual e refletir alternativas de enfrentamento, assim, defendemos que somente conseguiremos traçar formas de erradicar a violência de gênero, e todas as suas expressões, quando conseguirmos encarar este tripé de determinações sociais de forma concisa e articulada coletivamente, na direção da construção de uma nova ordem societária, sem dominação/exploração de gênero, raça e classe, erradicando assim, a atual base estrutural da violência.

\section{Referências}

BAIRROS, Luiza. Cultura e Raízes da Violência Contra as Mulheres. Disponível em: http://www.agenciapatriciagalvao.org.br/dossies/violencia/violencias/cultura-e-raizes-daviolencia/ - Acesso em 18 de julho de 2018. 
BANDEIRA, Lourdes Maria. Violência de gênero: a construção de um campo teórico e de investigação. Revista Sociedade e Estado, Brasília. V. 29 Nº 2 - Maio/Agosto, 2014.

BEZERRA, Vanessa; VELOSO, Renato. Gênero e Serviço Social: desafios a uma abordagem crítica. São Paulo, Saraiva, 2015.

BRASIL: Lei 11.340 de 7 de agosto de 2006. Lei Maria da Penha. Brasília, 2006.

HIRATA, Helena; KERGOAT, Daniele. Novas configurações da divisão sexual do trabalho. Cad. Pesqui. São Paulo, v.37, n.132, p.595-609, 2007. Disponível em: http://scielo.br/pdf/cp/v37n132/a0537132 - Acesso em 07 de setembro de 2018.

REZENDE, Daniela Leandro. Patriarcado e formação do Brasil: uma leitura feminista de Oliveira Vianna e Sérgio Buarque de Holanda. Revista Pensamento Plural, Rio Grande do Sul, ano 9, no17 - Julho/Dezembro, 2015.

ROS, Ana Carolina Pontes. Produção e reprodução social da violência: rebatimentos da naturalização de processos violentos na sociedade capitalista. In: ANAIS da V Jornada Internacional de políticas públicas, 2011.

SAFFIOTI, Heleieth. Contribuições feministas para o estudo da violência de gênero. Cadernos Pagu, Campinas, n. 16, p.115-136, 2001. Disponível em:

http://www.scielo.br/pdf/cpa/n16/n16a07.pdf - Acesso em 07 de setembro de 2018.

Violência de Gênero - lugar da práxis na construção da subjetividade. Lutas Sociais, $\mathrm{n}^{\circ}$ 2, PUC/SP, 1997, pp.59-79. Disponível em: http://www4.pucsp.br/neils/downloads/v2_artigo_saffioti.pdf - Acesso em 07 de setembro de 2018.

Disponível em:

Gênero, Patriarcado e Violência. São Paulo: Fundação Perseu Abramo, 2004. https://edisciplinas.usp.br/pluginfile.php/1741437/mod_resource/content/1/G\%C3\%AAnero\% 2C\%20Patriarcado\%2C\%20Viol\%C3\%AAncia\%20\%20\%28livro\%20completo\%29.pdf. Acesso em 07 de setembro de 2018.

SANTOS, José Luiz dos. O que é cultura. São Paulo, Editora Brasiliense, 6.ed, 1987.

VELOSO, Renato; BEZERRA, Vanessa. Gênero e Sociedade: Uma breve introdução à dimensão de gênero nas relações sociais. Revista Teoria e Sociedade, $\mathrm{n}^{\circ} 12$ - Janeiro/Junho, 2004. 